\title{
(2) OPEN ACCESS \\ Going toe-to-toe with a rare case of a complex regional pain syndrome limited to the hallux
}

\author{
Audrey Wetzel-Weaver (10, ${ }^{1,2}$ Sylvie Revaz, ${ }^{3}$ Michel Konzelmann, ${ }^{1,4}$ Francois Luthi ${ }^{1,5}$
}

${ }^{1}$ Department of Research,

Clinique romande de readaptation, Sion, Switzerland ${ }^{2}$ Department of Physical and Rehabilitation Medicine, Hopital Fribourgeois, Villars-sur-Glâne, Fribourg, Switzerland ${ }^{3}$ Department of Rheumatology and Expertise, Clinique romande de readaptation, Sion, Switzerland

${ }^{4}$ Department of Musculoskeletal Rehabilitation, Clinique

romande de readaptation, Sion, Switzerland

${ }^{5}$ Department of Physical and Rehabilitation Medicine, Lausanne University Hospital, Lausanne, Switzerland

Correspondence to Dr Audrey Wetzel-Weaver; audrey.wetzel@outlook.fr

Accepted 12 August 2021

Check for updates

(c) BMJ Publishing Group Limited 2021. Re-use permitted under CC BY-NC. No commercial re-use. See rights and permissions. Published by BMJ.

To cite: Wetzel-Weaver A,

Revaz S, Konzelmann M,

et al. BMJ Case Rep

2021;14:e242781.

doi:10.1136/bcr-2021-

242781

\section{SUMMARY}

We report the first case of a complex regional pain syndrome (CRPS) limited to the hallux using the Budapest criteria. Limited forms of CRPS are scarce in the literature and probably overlooked. There is currently no consensus to define these forms. Due to the particular metameric topography, common to the hand and the foot, we suggest the term 'metameric' CRPS to describe them. A uniform nomenclature would promote future research to study its prevalence and specific treatment in more detail.

\section{BACKGROUND}

Since Sudeck's description, ${ }^{1}$ the scientific literature has flourished around the intriguing pathology known as complex regional pain syndrome (CRPS). CRPS is most commonly diagnosed after an orthopaedic trauma $(0.15 \%$ of all such trauma occurrences) ${ }^{2}$ and can lead to a poor rehabilitation prognosis and generate significant costs. According to the Swiss national accident insurance database, healthcare and social costs of CRPS patients were, respectively, 13 times and 19 times higher than those of patients with similar injuries without CRPS. ${ }^{2}$ CRPS typically affects the extremities (hand and foot) and is characterised by persistent regional pain, disproportionate to the initial event. ${ }^{3}$ The signs and symptoms associated with CRPS are defined by the 2010 Budapest criteria along four categories: sensory, vasomotor, sudomotor/oedema and motor/trophic ${ }^{4}$ (box 1).

More localised forms of CRPS are rarer, less described and probably overlooked. Since the 1970s, various terms have been used in the literature to describe the latter without reaching a consensus (eg, partial, radial, focal, segmental or zonal CRPS), adding confusion about this condition. ${ }^{5-14}$ Interestingly, existing literature primarily focused on CRPS affecting the hand while localised CRPS of the foot has only been described occasionally, ${ }^{6} 81314$ but never since the adoption of the Budapest criteria. However, as the foot is the second most common location of the typical form of CRPS, ${ }^{15}$ it seems unlikely that these forms are found almost exclusively in the hand. We present the case of a CRPS limited to the hallux following a left foot contusion in a 30 -year-old man. The purpose of this case report is to draw attention to this condition and to assess the applicability of the Budapest criteria.

\section{CASE PRESENTATION}

A 30-year-old male metalworker was referred to our rehabilitation unit in May 2020 for diagnostic advice and interdisciplinary care due to persistent pain after a contusion of the left forefoot that had occurred 5 months earlier. X-rays did not show any fracture. The initial treatment consisted of the prescription of painkillers, physiotherapy and foot orthoses, but did not bring any improvement. Due to the persistent pain, he had adopted an avoidance step on the heel and the lateral edge of the foot to avoid any contact of the hallux with the ground. A CT scan showed only mottled osteopenia in the first radius of the foot initially suspected to be related to the immobilisation. An MRI showed bone oedema of the first metatarsal, first phalanx and medial sesamoid accompanied by soft tissue swelling predominantly on the plantar side interpreted as the stigmata of the bone contusion (figure 1).

During our first clinical encounter, the patient reported continuous pain (Numerical Rating Scale: 6/10), sensory disturbances with a neuropathic component (DN4: 7/10), changes in temperature and colour of the hallux, increased sweating and oedema. He described difficulties with moving his toes and used crutches to move around, avoiding any contact with the forefoot (walking and touching). Clinical examination confirmed localised allodynia and asymmetry of the hallux temperature on the infrared thermometer $\left(33.6^{\circ} \mathrm{C}\right.$ on the affected site vs $32.1^{\circ} \mathrm{C}$ on the unaffected one), but not the colour change. The other signs were not very pronounced, but could be objectified: oedema $(+1 \mathrm{~cm})$, hypersudation (visually and by touch), decreased range of motion (especially for the metatarsophalangeal and interphalangeal ray of the hallux) and weakness of the flexors and extensors of the hallux.

The presence of unfavourable cognitive and affective factors in an overweighed and recently immigrated patient from the Balkans without professional certification were found on questionnaires: high kinesiophobia and catastrophism (Tampa Scale of Kinesiophobia (46/68 points) and Pain Catastrophizing Scale (27/52)), high anxiety and moderate depressive symptoms (Hospital Anxiety and Depression scale (A 14/21; D: 10/21)). At this stage, the diagnosis of CRPS of the foot limited to the first radius of the left forefoot was evoked (Budapest criteria 1, 2 and 3 were met: box 1). Due to the rarity of this situation and in order to fulfil the Budapest criterion 4 ('there is no other diagnosis that better explains the signs and symptoms'), we considered it necessary to pursue the investigations.

\section{INVESTIGATIONS}

As the review of the previous imagery did not bring any new elements, the following investigations 
Box 1 Budapest criteria (2010 version) (adapted from Harden et al) ${ }^{4}$

Budapest criteria

1. Continuing pain, which is disproportionate to any inciting event

2. At least one symptom in three of the four following categories:

Sensory: reports of hyperesthesia and/or allodynia

Vasomotor: reports of temperature asymmetry and/or skin

colour changes and/or skin colour asymmetry

Sudomotor/oedema: reports of oedema and/or sweating

changes and/or sweating asymmetry

Motor/trophic: reports of decreased range of motion and/or motor dysfunction (weakness, tremor, dystonia) and/or trophic changes (hair, nail, skin)

3. Must display at least one sign at the time of evaluation in two or more of the following categories:

Sensory: evidence of hyperalgesia (to pinprick) and/or allodynia

(to light touch and/or deep somatic pressure and/or joint

movement)

Vasomotor: evidence of temperature asymmetry and/or skin colour changes and/or asymmetry

Sudomotor/oedema: evidence of oedema and/or sweating changes and/or sweating asymmetry

Motor/trophic: evidence of decreased range of motion and/or motor dysfunction (weakness, tremor, dystonia) and/or trophic changes (hair, nail, skin)

4. There is no other diagnosis that better explains the signs and symptoms

were ordered. To rule out septic or inflammatory arthritis, we conducted a blood test, which proved to be normal, in particular, no inflammatory syndrome and no alteration of the phosphocalcium balance. However, the uric acid level was at the upper limit of the reference ranges: $400 \mu \mathrm{mol} / \mathrm{L}$ (range: $210-420$ $\mu \mathrm{mol} / \mathrm{L}$ ). Electroneuromyography did not show any evidence for neurological damage. A three-phase Tc99 bone scintigraphy (BS) showed an increased uptake of the tracers on the first metatarsus and first toe only in the late bone phase (figure 2). This has been interpreted as being compatible with CRPS diagnosis although not specific. Given this and after discussion with our rheumatologist colleagues, we proceeded to a dual energy CT-scan ${ }^{16} 17$ to look for uric acid crystals. This did not find any arguments in favour of a gout or any other microcrystalline arthropathy nor area of suspected cortical erosion. There was still a discrete speckled demineralisation of the first left metatarsal head and

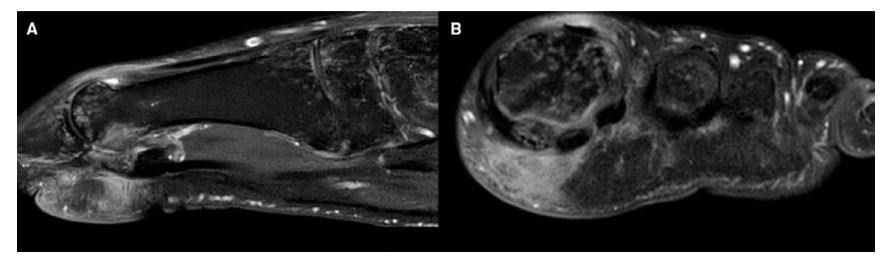

Figure $1 \quad(A, B)$ The forefoot sagittal $(A)$ and axial (B) $T 1$ fat saturation injected MRI showed a mottled bone oedema of the first metatarsal head and the medial sesamoid, associated with a swelling of the surrounding soft tissues, predominantly on the plantar side. The juxtaarticular position at the base of the first metatarsal is particularly noticeable, but also at the base of the first cuneiform and navicular bone.

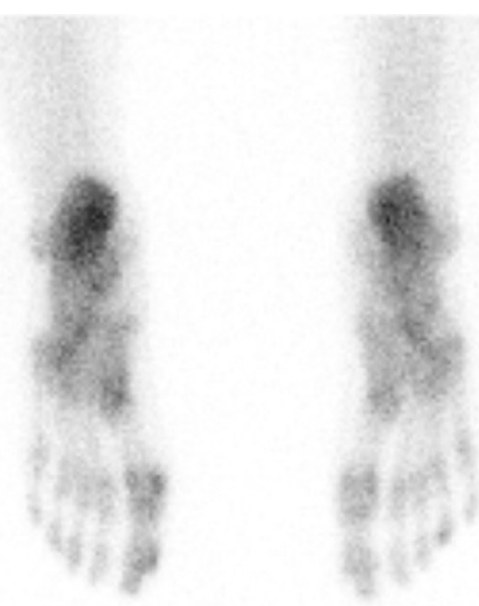

Figure 2 Bone scintigraphy, late bone phase, showing uptake of the tracers to the plantar side of the left hallux.

toe (figure 3). Finally, in order to complete the assessment, we performed an ultrasonography ${ }^{18}$ of the soft tissues, which did not reveal any effusion to puncture or deposits of crystal. Taken together, these results allowed us to definitively exclude the possibility of the most probable differential diagnosis, an atypical presentation of gout.

\section{DIFFERENTIAL DIAGNOSIS}

A painful condition of the first radius of the foot can be encountered under many clinical conditions: ${ }^{19}$ trauma (contusion, sprain and fracture), osteoarthritis (hallux rigidus), rheumatic diseases (microcrystalline arthritis, spondylarthropathy and rheumatoid arthritis), infection (with common germs, but also tuberculosis, which exceptionally can cause dactylitis), ${ }^{20}$ osteonecrosis (metatarsal or sesamoid), tumour (metastasis, sarcoma and giant cell tumour or osteoid osteoma). ${ }^{21}$ Neuropathy or vascular pathology can also be considered. In our case, all these diagnoses could be ruled out. Gout, which can have an atypical presentation, ${ }^{22}$ was the last one. It is important to note that the CT, MRI and BS images (figures 1-3) were all compatible with the diagnosis finally retained of a localised CRPS even though none of them individually could be considered specific enough to confirm this diagnosis.

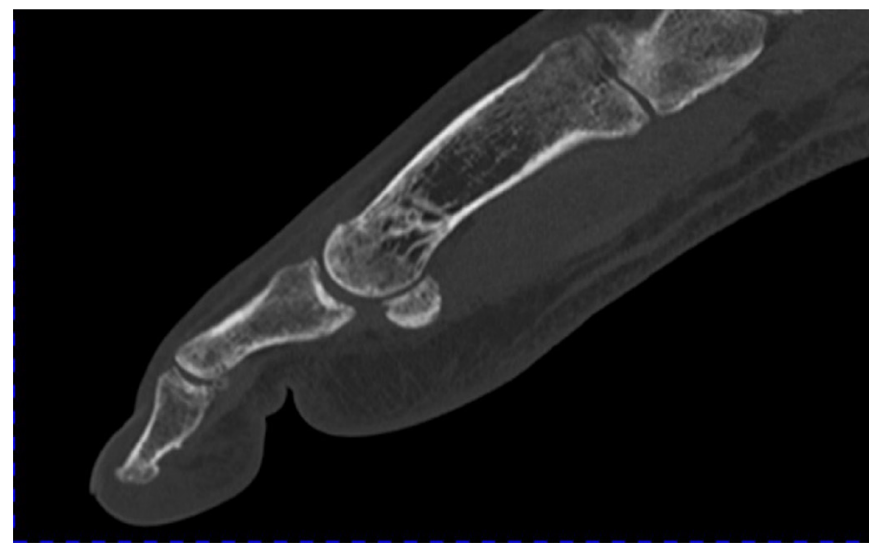

Figure 3 The sagittal CT of the foot showed a generalised osteopenia of the first toe and a mottled aspect, especially localised on the plantar face of the metatarsophalangeal head, the first phalange of the hallux and the medial sesamoid bone. 


\section{TREATMENT}

Treatments were administered in accordance with actual knowledge on CRPS and neuropathic pain. ${ }^{23}{ }^{24}$ Local treatments were chosen preferably because of the small area of clinical manifestations (first topical lidocaine, topical ketamine and finally botulinum toxin injections ${ }^{25}$ ). In a second step, bisphosphonates (zoledronic acid) and then steroids were also administered. ${ }^{24}$ However, none of these attempts resulted in significant therapeutic benefits. Because the patient presented many side effects after oral and systemic treatment, it was decided to avoid other drugs except non-steroidal anti-inflammatory drugs (NSAIDs). It was also considered that there was no indication for invasive pain management. In parallel, the patient benefited from physiotherapy (graded exercises, walking school and transcutaneous electrical nerve stimulation), occupational therapy (desensitisation and motor imagery) and footwear adaptation (adapted orthopaedic shoes and plantar insole). Explanations on the mechanisms of persistent pain and CRPS were given with an interpreter. However, due to the language barrier, low educational attainment and poor health literacy, this approach was limited, as were the opportunities for other therapies, such as cognitive-behavioural therapy. Interdisciplinary care lasted 6 weeks. At this time, the patient was able to walk without a crutch, for a limited travel duration (15-20 minutes), but still avoided the toe-off walking phase. He reported a moderate reduction in pain (20\%-30\%). It was then decided to continue the follow-up, while spacing out therapy sessions at two times a week intervals.

\section{OUTCOME AND FOLLOW-UP}

The patient was seen three times with the presence of a family member and an interpreter to ensure better communication with the medical staff. In the last consultation, in December 2020, the patient still described most of the CRPS symptoms. However, his reported pain decreased to $3 / 10$, representing a halving of the initial stage. NSAIDs were only taken occasionally. Walking improved with a duration estimated to be 30-60' depending on the day, but always with difficulties with the late toe-off phase. The patient said he was gradually returning to a normal daily life. Although he reported the persistence of most of the initial symptoms, the disappearance of vasomotor signs and oedema/ sudation has been confirmed, but not for moderate sensory and light motor signs. The persistence of the latter (discrete weakness and slightly reduced toe mobility) can be also interpreted as a manifestation of well-documented kinesiophobia and fear of pain.

\section{DISCUSSION}

Several lessons can be learnt from this case. First, CRPS of the foot with a limited extension even if rarely cited, does indeed exist and should be included as a differential diagnosis, particularly in the case of localised and persistent pain after trauma. The fact that today there is such a limited recording of CRPS affecting the foot in the literature ${ }^{6131426}$ may lead clinicians to overlook this diagnosis. Even for classical forms of CRPS, a recent study has shown that foot localisation is an independent factor in diagnostic delay. ${ }^{27}$ Given that the foot is the second most frequent location for typical CRPS, ${ }^{15}$ and that the prevalence of localised CRPS in the hand is estimated at $12 \%,{ }^{11}$ we recommend that future studies should look further into prevalence of localised CRPS of the foot.

Second, the Budapest criteria ${ }^{28}$ also appear applicable for this localised form of CRPS. To our knowledge, it is the first description of a CRPS localised on the hallux since the validation of the Budapest criteria in 2010. But before that, the last case dates back to $1990 .^{14}$ Due to a limited extension of clinical signs (ie, localised only in the hallux), these forms require a very careful clinical examination to avoid misdiagnosis or delay. Once recognised, a rigorous differential diagnosis approach, to avoid the other pitfalls frequently encountered (ie, overdiagnosis of the $\mathrm{CRPS}^{29}$ ), must be chosen. It should also be remembered that although no imagery can be considered as specific, ${ }^{30}$ the findings on CT, MRI and BS were all compatible with this syndrome (figures 1-3). Imagery, which is infrequently emphasised in the literature on CRPS, was a key factor in our case to exclude other possible clinical conditions and comply with the necessary Budapest criterion 4 (box 1 ).

Prognosis of this localised form of CRPS needs to be clarified. Literature is limited, few authors consider the prognosis to be better, ${ }^{67}$ others not. ${ }^{11}$ A series of 16 partial hand CRPS showed, for example, that 50\% had not returned to work 4-9 years after the precipitating event. ${ }^{11}$ Prognosis is also related to the importance of overprotective psychological responses (avoidance of movement and avoidance of pain) to cope with the perception of a threat of tissue damage, ${ }^{31}$ as observed here. Negative illness perception and specifically attributing more symptoms to CRPS was also recently related to greater pain intensity and reporting of higher disability. ${ }^{32}$ Taking a step back, as we try to understand why the patient's recovery has taken longer than expected, we can point to several factors, which probably played a role in the unfavourable prognosis and evolution. It is interesting to note that the non-pharmacological treatments, typically the most suitable options with maladaptive coping strategies, were the only ones that brought some benefit in our case. In addition, contextual factors, such as linguistic and cultural background, were undeniable barriers here. Involving community interpreters

\section{Patient's perspective}

This pain, even though localised, has slowed me down in all my activities, first of all professionally, but also personally and socially. Putting a name to what I have, 'complex regional pain syndrome', has allowed me to move forward even if it hasn't made my pain disappear entirely. However, this syndrome is still difficult for me to understand. For example, it is still difficult for me and my family to understand that doctors talk to me about psychological factors associated with pain when I know that my pain is in my foot. I agreed to publish this case so that other people who find themselves in the same situation as me can also benefit from the diagnosis and be able to get on with their life.

\section{Learning points}

Localised forms of complex regional pain syndrome (CRPS) are scarce in the literature, but probably overlooked.

- The diagnostic of these forms can be retained after having fulfilled the Budapest criteria and eliminating any other differential diagnosis.

- These localised forms of CRPS, both for the hand and foot, show a metameric topography.

- We propose the term 'metameric' CRPS in order to have a more consensual designation.

- The treatment must be multimodal and pluridisciplinary while ideally taking into account the biopsychosocial factors related to chronic pain even if it is localised. 
and the family whenever possible are important to try to reduce them.

Finally, this localised form does not present a true consensual designation. The distribution of symptoms and signs followed a metameric distribution as it is also the case with the hand. ${ }^{11}$ Some authors suggest the role of innervation in this particular distribution, which can affect from 1 to 3 digital rays of the hand. ${ }^{33-35}$ This finding could help to choose the best way to simply describe this syndrome. A 'metameric' CRPS could be the best choice, as all the other terms used to date (partial, radial, focal, segmental or zonal) can be confusing and may contribute to the lack of knowledge about this syndrome.

Finally, the interest of this case report lies in drawing the physicians' attention to the existence of these discrete forms of localised CRPS of the foot, which may be underestimated by the lack of awareness and the absence of consensus to define them. With a consensual name, more studies should look into its prevalence and specific treatment.

Contributors Conception or design of the work: AW and FL. Data collection: AW and FL. Data analysis and interpretation: AW and FL. Drafting the article: AW. Critical revision of the article: AW and FL. Final approval of the version to be published: AW, FL, SR and MK.

Funding The authors have not declared a specific grant for this research from any funding agency in the public, commercial or not-for-profit sectors.

Competing interests None declared.

Patient consent for publication Obtained.

Provenance and peer review Not commissioned; externally peer-reviewed.

Open access This is an open access article distributed in accordance with the Creative Commons Attribution Non Commercial (CC BY-NC 4.0) license, which permits others to distribute, remix, adapt, build upon this work non-commercially, and license their derivative works on different terms, provided the original work is properly cited and the use is non-commercial. See: http://creativecommons.org/ licenses/by-nc/4.0/.

\section{ORCID iD}

Audrey Wetzel-Weaver http://orcid.org/0000-0002-0918-8375

\section{REFERENCES}

1 Sudeck P. Uber die akute entzundliche Knochenatrophie. Arch Klin Chir 1900;62:147-56.

2 Scholz-Odermatt SM, Luthi F, Wertli MM, et al. Direct health care cost and work incapacity related to complex regional pain syndrome in Switzerland: a retrospective analysis from 2008 to 2015. Pain Med 2019:20:1559-69.

3 Bruehl S. Complex regional pain syndrome. BMJ 2015;351:h2730.

4 Harden NR, Bruehl S, Perez RSGM, et al. Validation of proposed diagnostic criteria (the "Budapest Criteria") for Complex Regional Pain Syndrome. Pain 2010;150:268-74

5 Doury P, Pattin S, Delahaye RP, et al. [Partial algodystrophy of the knee]. Nouv Presse Med 1978;7:3156

6 Lequesne M, Kerboull M, Bensasson M, et al. Partial transient osteoporosis. Skeletal Radiol 1977;2: :1-9.

7 Lequesne M. L'algodystrophie décalcifiante partielle. Rev Rhum 1979:46:111-21.

8 Doury P, Dirheimer Y, Pattin S. Algodystrophy. Diagnosis and therapy of a frequent disease of the locomotor apparatus. Berlin-Heidelberg-New York: Springer, 1981.

9 Lagier R. Partial algodystrophy of the knee. An anatomico-radiological study of one case. J Rheumatol 1983;10:496-9.
10 Gougeon J. Les formes recidivantes des algoneurodystrophies des membres inferieurs. Rhumatologie 1966;18.

11 Konzelmann M, Deriaz O, Luthi F. Diagnosis of partial complex regional pain syndrome type 1 of the hand: retrospective study of 16 cases and literature review. BMC Neurol 2013;13:13-28.

12 Bui R, Coffman J, Berry A, et al. Complex focal pain syndrome: an unusual variant of complex regional pain syndrome. Cureus 2020;12:e9510.

13 Lagier R. Post-traumatic Sudeck's dystrophy localized in the metatarso-phalangeal region. An anatomico-radiological study of a case. Rofo 1983;138:496-9.

14 Kleinman D, Rosen RC, Cohen JM. Combined anesthetic and surgical treatment of reflex sympathetic dystrophy following a healed crush injury of the foot. J Foot Surg 1990;29:55-8

15 Ott S, Maihöfner C. Signs and symptoms in 1,043 patients with complex regional pain syndrome. J Pain 2018:19:599-611.

16 Chou H, Chin TY, Peh WCG. Dual-energy CT in gout - A review of current concepts and applications. J Med Radiat Sci 2017:64:41-51.

17 Hussain K, Shahid S, Chang W. Role of DECT in a patient with atypical gout flare. BMJ Case Rep 2019;12:e231850.

18 Christiansen SN, Østergaard M, Terslev L. Ultrasonography in gout: utility in diagnosis and monitoring. Clin Exp Rheumatol 2018;36(Suppl 114):61-7.

19 Ashman CJ, Klecker RJ, Yu JS. Forefoot pain involving the metatarsal region: differential diagnosis with MR imaging. Radiographics 2001;21:1425-40.

20 Faroug R, Psyllakis P, Gulati A, et al. Diagnosis and treatment of tuberculosis of the foot and ankle-A literature review. Foot 2018;37:105-12.

21 Xarchas KC, Kyriakopoulos G, Manthas S, et al. Hallux osteoid osteoma: a case report and literature review. Open Orthop J 2017;11:1066-72.

22 Dalbeth N, Merriman TR, Stamp LK. Gout. Lancet 2016:388:2039-52.

23 Cruccu G, Truini A. A review of neuropathic pain: from guidelines to clinical practice. Pain Ther 2017:6:35-42.

24 Wertli MM, Kessels AGH, Perez RSGM, et al. Rational pain management in complex regional pain syndrome 1 (CRPS 1)--a network meta-analysis. Pain Med 2014;15:1575-89.

25 Attal N, de Andrade DC, Adam F, et al. Safety and efficacy of repeated injections of botulinum toxin $A$ in peripheral neuropathic pain (BOTNEP): a randomised, doubleblind, placebo-controlled trial. Lancet Neurol 2016;15:555-65.

26 Thumtecho S, Schimmel J, Trakulsrichai S. Complex regional pain syndrome following a centipede bite: a case report. Clin Toxicol 2020;58:777-9. doi:10.1080/15563650.20 19.1686515

27 Varenna M, Crotti C, Ughi N, et al. Determinants of diagnostic delay in complex regional pain syndrome type 1: an observational study of 180 consecutive new cases. J Clin Rheumatol 2020. doi:10.1097/RHU.0000000000001558. [Epub ahead of print: 04 Sep 2020].

28 Goebel A, Birklein F, Brunner F, et al. The Valencia consensus-based adaptation of the IASP complex regional pain syndrome diagnostic criteria. Pain 2021. doi:10.1097/j. pain.0000000000002245. [Epub ahead of print: 15 Mar 2021].

29 Mailis-Gagnon A, Lakha SF, Allen MD, et al. Characteristics of complex regiona pain syndrome in patients referred to a tertiary pain clinic by community physicians, assessed by the Budapest clinical diagnostic criteria. Pain Med 2014; 15:1965-74.

30 Agten CA, Kobe A, Barnaure I, et al. MRI of complex regional pain syndrome in the foot. Eur J Radiol 2020;129:109044.

31 Bean DJ, Johnson MH, Heiss-Dunlop W, et al. Do psychological factors influence recovery from complex regional pain syndrome type 1? A prospective study. Pain 2015:156:2310-8.

32 Antunovich DR, Horne JC, Tuck NL. Are illness perceptions associated with pain and disability in complex regional pain syndrome? A cross-sectional study. Pain Med 2020

33 Helms CA, O’Brien ET, Katzberg RW. Segmental reflex sympathetic dystrophy syndrome. Radiology 1980;135:67-8.

34 Kline SC, Holder LE. Segmental reflex sympathetic dystrophy: clinical and scintigraphic criteria. J Hand Surg Am 1993;18:853-9.

35 Bianchi S, Abdelwahab IF, Garcia J. Partial transient osteoporosis of the hand. Skeletal Radiol 1999;28:324-9. 
Copyright 2021 BMJ Publishing Group. All rights reserved. For permission to reuse any of this content visit https://www.bmj.com/company/products-services/rights-and-licensing/permissions/

BMJ Case Report Fellows may re-use this article for personal use and teaching without any further permission.

Become a Fellow of BMJ Case Reports today and you can:

- Submit as many cases as you like

Enjoy fast sympathetic peer review and rapid publication of accepted articles

Access all the published articles

Re-use any of the published material for personal use and teaching without further permission

Customer Service

If you have any further queries about your subscription, please contact our customer services team on +44 (0) 2071111105 or via email at support@bmj.com.

Visit casereports.bmj.com for more articles like this and to become a Fellow 